This item was submitted to Loughborough's Research Repository by the author.

Items in Figshare are protected by copyright, with all rights reserved, unless otherwise indicated.

\title{
A comparative force assessment of 4 methods to move a patient up a bed
}

PLEASE CITE THE PUBLISHED VERSION

https://doi.org/10.1007/978-3-319-96077-7_68

\section{PUBLISHER}

(C) Springer

\section{VERSION}

AM (Accepted Manuscript)

\section{PUBLISHER STATEMENT}

This is a pre-copyedited version of a contribution published in Bagnara S. ... et al (eds). Proceedings of the 20th Congress of the International Ergonomics Association (IEA 2018). published by Springer. The definitive authenticated version is available online via https://doi.org/10.1007/978-3-319-96077-7_68

\section{LICENCE}

CC BY-NC-ND 4.0

\section{REPOSITORY RECORD}

Fray, Mike, and George Holgate. 2019. "A Comparative Force Assessment of 4 Methods to Move a Patient up a Bed". figshare. https://hdl.handle.net/2134/35063. 


\title{
A comparative force assessment of 4 methods to move a
}

\section{patient up a bed}

\author{
Mike Fray ${ }^{1}$ and George Holgate ${ }^{1}$ \\ ${ }^{1}$ Loughborough Design School, Loughborough University UK M.J.Fray@lboro.ac.uk
}

\begin{abstract}
.
This study compared four different postures and positions regularly suggested for moving a patient up towards the head of the bed, using both novice and expert users.

The trial was carried out in a laboratory using 21 participants (10 novices and 11 experts). All participants completed all conditions $(n=4)$ three times each $(n=3$ repetitions). The physical force at each hand was recorded using electronic four compression/tension meters, recorded on DasyLab software. After each condition a subjective review questionnaire was completed. The data was processed with excel and SPSS to evaluate the differences between the conditions.
\end{abstract}

A significant statistical reduction was found when comparing combined force for all carers $(\mathrm{F}(3,27)=24.63, \mathrm{p}<.05)$ and the load per individual $(\mathrm{F}(2.21,44.21)=27.26$, $\mathrm{p}<.05)$. However there was found to be no statistical difference between left and right hand or upper or lower hand.

Transfers carried out with the carer pulling the patient towards them corresponded with a lower force to complete the transfer. This study suggests that a position with an oblique offset base and an action of pull and push in line with the carer could be the preferred position for a wide range of patient transfers.

Keywords: Biomechanics, patient transfers, Perceived effort 


\section{Introduction}

Warming et al (2009) defined patient handling as consisting of two tasks '(1) transfer tasks, which is when the nurse assists the patient moving from one position to another and (2) care tasks, which is when the nurse assists the patient in doing daily activities or necessary professional tasks for the well-being of the patient'. The focus of this report will be on patient transfer tasks, in particularly moving patients horizontally towards the head of the bed.

Care staff are frequently exposed to significant load during their daily work (Fragala et al. 2005). The handling and moving of patients in bed are part of these frequently carried out tasks, with Smith (2005) stating the 'act of pulling a patient up to the head of the bed, is a frequently performed patient handling task' and 'nurses are exposed to high risk patient handling tasks at a high frequency'It is considered that nursing tasks can be high risk (Fragala et al,2005), Owen and Staehler, 2003).

Various studies have highlighted that carers are at risk of potential injuries when carrying out transfer tasks (Garg et al., 1991, Schibye et al., 2003, Waters 2007). Other supporting studies (Alamgir et al 2007, Jager et al 2013) confirm the fact that carers are vulnerable to sustaining MSI due to 'transferring and repositioning tasks during patient/ resident/ client care'. The potential risk of injury is accentuated through not using slide sheets; with Jordan et al. (2011) stating transfer tasks not using slide sheets are responsible for the 'highest lumbar load of various patienthandling tasks'.

In order to reduce the impact of poor/ awkward patient handling and in particularly patient transfer, training and certain patient handling techniques/ aides have been put in place to help aid and inform carers (Smith, 2005, Cohen et al. 2010, WS Vic, 2009). Pellino et al (2006) states using transfer aides reduce physical stress on the part of nurses (Nelson et al, 2003). Information, education and training in proper use of aids/ equipment are essential to promote behavioral and attitude changes among staff (ISO 2012, ANA 2013). Several studies reported the combination of both using equipment and education is more effective safer patient handling (Black et al 2011, Lim et al 2011, Garg \& Kapellusch, 2012).

\section{Methods}

\subsection{Aims}

The overall aim of this study is to quantify and compare four different conditions in terms of the force required to transfer a patient up towards the head of the bed, using both novice and expert users.

\subsection{Objectives}


To quantify the amount of force required in each condition of transfer for both novice and expert users.

To compare and rank the different conditions from best to worst in terms of force needed.

\subsection{Conditions}

The postures/positions to move someone towards the head of the bed were selected having reviewed current best practices (Brooks \& Orchard. 2011, NHS. 2010, Smith et al., 2011). A focus group of professionals within the subject area was used to provide evaluation on the methods. The force required to move the patient up the bed was evaluated in pilot studies. Through testing a final suitable weight $(\approx 68 \mathrm{~kg})$ was decided. On evaluation a weighted mannequin was used to standardise the trial. Market standard slide sheets were placed under the mannequin and the force devices were attached to standard positions on a non-slip under sheet. The conditions selected for the trial were:

1. Parallel Stepping- Two participants, on either side of the bed with hands at the shoulder and hip of the patient the carer's step up the bed sliding the patient along.

2. Rotation- Two participants, one on either side of the bed with hands at the shoulder and hip of the patient participants turn towards the head of the bed, without moving the feet.

3.2 Person Oblique Pull Up Bed- Two participants at each top corner with an oblique offset base. To move the carers take a step backwards keeping their arms straight.

4. Single Person Pull Up Bed- This transfer uses one participant, at the head of the bed with hands shoulder width apart. When ready the participant steps backwards, keeping their arms straight.

\subsection{Data Collection}

In line electronic force meters allowed force data to be collected from each hand for the four conditions. Ethical approval was achieved through the University systems. The force devices were calibrated daily and between participants. Each condition was completed three times, with an average taken, any large variations in the data caused a repetition of the action. A convenience, non-probability sampling strategy was used, by sending a number of emails to potential participants and using those who replied in the trial.

During the trial participants were given time to familiarise themselves with the transfer. Each transfer would then be carried out three. Once completed the participants being asked to fill out either a short novice or expert review questionnaires. The transfer was repeated if any errors or significant differences from normal movement or participant body position were observed, to give consistency in the analysis.

\subsection{Subjective Data}

After the participants carried out each condition they were asked to complete a subjective review depending on their level of experience (novice \& expert). These included a Borg rating scale and likert scale questions reporting the effort, security 
and safety of each condition, with the expert review also including how likely the particular condition was to be used in their regular practice and workplace.

\subsection{Forces Assessment}

Forces in Newtons were recorded at 20 reading per second in the software. Each transfer was examined with the length of transfer, average force and peak force being calculated and recorded. These data were used to compare the conditions:

- Total load per transfer - all hands all carers

- Individual load per transfer - both hands per carer

- Individual hand load for conditions 1, 2 and 4

\subsection{Statistical Analysis}

All Shapiro-Wilks test for normality was conducted on all data to evaluate for normal distribution. This implied the use of a repeated measures ANOVA test or a Friedman test. For the total load per transfer and also individual load per transfer, a repeated measures ANOVA was used to test for significance between the average force of each condition. Independent Samples T-tests were conducted to compare the average force exerted between the novice and expert participants. For non-normal distributions Wilcoxon Signed Rank test or Mann-Whitney U test were used. Post hoc analysis used the Bonferroni corrections.

\section{$3 \quad$ Results}

A total of 21 participants were used. These were split into novices $(\mathrm{n}=10)$ and experts $(n=11)$, with each completing each transfer three times.

\subsection{Subjective Review- Qualitative Data}

Table 1. Mean Response Of The Borg Rating Scale for All Participants

\begin{tabular}{lcccc}
\hline \multicolumn{1}{c}{ Condition } & Novice & \multicolumn{3}{c}{ Expert } \\
& Mean & SD & Mean & SD \\
\hline 1. Parallel stepping & 2.8 & 0.75 & 3.7 & 0.96 \\
2. Rotation & 4.0 & 0.90 & 6.1 & 2.02 \\
3. 2-person oblique pull up bed & 1.9 & 0.75 & 3.0 & 1.57 \\
4. Single person pull up bed & 2.8 & 1.16 & 2.7 & 0.68 \\
\hline
\end{tabular}


A repeated measures ANOVA for novice carers showed Borg scores significantly differed between the conditions $(F(1.94,17.43)=10.47, p<.05)$. Post hoc tests using the Bonferroni correction revealed significant difference between conditions 2 and 3 $(\mathrm{p}=.002)$ and also conditions 3 and $4(\mathrm{p}=.004)$. Therefore, perceived force for condition 3 was easier than conditions 2 and 4, but not condition 1. For the experts, the ANOVA determined the scores again significantly differed statistically between conditions $(\mathrm{F}(3,30)=14.65, \mathrm{p}<.05)$. Post hoc tests using the Bonferroni correction revealed significant difference between conditions 2 and all of the other conditions $(1: \mathrm{p}=.016,3: \mathrm{p}=.013,4: \mathrm{p}=.003)$. However, there was no significant difference between the other conditions. The perception of the rotation task showed it as much worse. Looking at the both groups together it can be seen that condition 2 scored the highest for both (4.0 and 6.1 respectively). This would suggest all participants felt they put more effort into this transfer. Alternatively, it could suggest novices felt condition 3 was the easiest whereas experts preferred condition 4.

Table 2. Subjective Response for All Four Conditions For Novice Participants

\begin{tabular}{lcccc}
\hline \multicolumn{1}{c}{ Condition } & \multicolumn{2}{c}{ Comfort } & \multicolumn{2}{c}{ Safety } \\
& Mean & SD & Mean & SD \\
\hline 1. Parallel stepping & 3.6 & 1.08 & 3.7 & 0.95 \\
2. Rotation & 2.1 & 0.57 & 2.5 & 0.71 \\
3. 2-person oblique pull up bed & 4.3 & 0.95 & 4.1 & 0.99 \\
4. Single person pull up bed & 3.5 & 0.97 & 3.8 & 0.79 \\
\hline
\end{tabular}

Table 3 shows that novice participants felt condition 3 was the most comfortable (4.3) and safest (4.1), whereas condition 2 was the least comfortable (2.1) and least safe (2.5).

Table 3. Subjective Response Of The Four Conditions For Expert Participants

\begin{tabular}{|c|c|c|c|c|c|c|c|c|}
\hline \multirow[t]{2}{*}{ Condition } & \multicolumn{2}{|c|}{ Comfort } & \multicolumn{2}{|c|}{ Safety } & \multicolumn{2}{|c|}{$\begin{array}{l}\text { Individual } \\
\text { acceptance }\end{array}$} & \multicolumn{2}{|c|}{$\begin{array}{l}\text { Organisational ac- } \\
\text { ceptance }\end{array}$} \\
\hline & Mean & $\mathrm{SD}$ & Mean & SD & Mean & $\mathrm{SD}$ & Mean & SD \\
\hline 1. Parallel stepping & 2.8 & 0.98 & 3.1 & 0.83 & 2.5 & 1.21 & 3.2 & 1.34 \\
\hline 2. Rotation & 1.7 & 0.91 & 1.7 & 0.91 & 1.5 & 0.69 & 2.9 & 1.70 \\
\hline 3. 2-person oblique pull up bed & 3.6 & 0.93 & 3.6 & 0.92 & 3.2 & 1.08 & 2.9 & 0.94 \\
\hline 4. Single person pull up bed & 3.8 & 0.54 & 4.1 & 0.54 & 3.4 & 0.92 & 3.4 & 1.03 \\
\hline
\end{tabular}

For the expert participants it was found that condition 4 not only scored the highest in terms of comfort (3.8) and safety (4.1), but also when considering individual (3.4) and organisational acceptance (3.4). However, resembling the novice participants, condition 2 also scored the worst across the different aspects. The Spearman's Rho test (Table 4) was repeated for the expert participants, for all conditions, to find the relationship between comfort, safety, personal and organisational acceptance. Similar to the novice participant, there was very strong positive correlation between comfort and safety. Personal acceptance was also found to have strong positive correlation with comfort, safety and organisational acceptance. With moderate positive correlation being found between organisational acceptance and comfort and safety. 
Table 4. Result Of The Spearman's Rho Test For Expert Participants

\begin{tabular}{llcccc}
\hline \multirow{2}{*}{ Comfort } & & Comfort & Safety & Individual & Organisational \\
& Correlation Coefficient & 1.000 & $.950^{* *}$ & $.755^{* *}$ & $.499^{* *}$ \\
\multirow{3}{*}{ Safety } & Sig. (2-tailed) &. & .000 & .000 & .001 \\
& Correlation Coefficient & $.950^{* *}$ & 1.000 & $.761^{* *}$ & $.520^{* *}$ \\
& Sig. (2-tailed) & .000 &. & .000 & .000 \\
\multirow{5}{*}{ Organividual } & Correlation Coefficient & $.755^{* *}$ & $.761^{* *}$ & 1.000 & $.637^{* *}$ \\
& Sig. (2-tailed) & .000 & .000 &. & .000 \\
& Correlation Coefficient & $.499^{* *}$ & $.520^{* *}$ & $.637^{* *}$ & 1.000 \\
& Sig. (2-tailed) & .001 & .000 & .000 &. \\
\hline
\end{tabular}

\subsection{Force Data}

The force data was investigated as; total load per transfer, individual load and individual hands. Although the peak force would be the major cause of injury, it was not used in the analysis as, for all transfers, this force was far away from the $1.8 \mathrm{kN}$ limit value set out in ISO 11228-2 (2007) and reported in Jäger et al’s (2001) study.

\subsubsection{Total load per transfer}

Shapiro-Wilks test found normality in all conditions ( $\mathrm{p}>.05)$. The mean average total load per transfer differed significantly between the four conditions $(F(3,27)=24$.63, $\mathrm{p}<.05)$. Post hoc tests using the Bonferroni correction revealed significant differences between condition 1 and $3(\mathrm{p}=.001)$ and $4(\mathrm{p}=.001)$. Also between condition 2 and 3 $(\mathrm{p}=.002)$ and $4(\mathrm{p}=.003)$. However there was no significant difference between condition 1 and $2(\mathrm{p}=.487)$ and also condition 3 and $4(\mathrm{p}=1.000)$. Therefore conditions 3 and 4 were similar, but significantly lower in the total amount of force exerted per transfer than conditions 1 and 2, which were also similar. Thus suggesting it is easier to carry out transfers from the top of the bed as opposed to at the side of the bed.

Table 5. Mean average Total Load Per Transfer

\begin{tabular}{lcccccc}
\hline \multicolumn{1}{c}{ Condition } & \multicolumn{2}{c}{ Novice } & \multicolumn{2}{c}{ Expert } & \multicolumn{2}{c}{ Combined } \\
& Mean & SD & Mean & SD & Mean & SD \\
\hline 1. Parallel stepping & 184.5 & 19.2 & 127.1 & 26.4 & 155.8 & 37.3 \\
2. Rotation & 219.0 & 70.5 & 164.4 & 52.4 & 191.7 & 65.2 \\
3. 2-person oblique pull up bed & 84.5 & 18.6 & 79.3 & 5.7 & 81.9 & 13.2 \\
4. Single person pull up bed & 78.6 & 21.9 & 68.0 & 13.0 & 73.0 & 20.9 \\
\hline
\end{tabular}


An Independent Samples T-test (Table 6) was conducted to compare novice and expert participants in terms of total load per transfer for each condition. It was found that the total load per transfer for condition 1 was significantly different for novice and expert participants $(\mathrm{p}<.05)$. For the other conditions there proved to be no difference between novice and experts ( $>>.05)$. This suggests that novice participants exert more force per transfer than experts for all of the conditions.

Table 6. Independent Samples T-test For Novice Vs. Experts For Total Load Per Transfer

\begin{tabular}{lccc}
\multicolumn{1}{c}{ Condition } & $\mathrm{t}$ & $\mathrm{df}$ & Sig.(2-tailed) \\
\hline 1. Parallel stepping & 3.929 & 8 & .004 \\
2. Rotation & 1.388 & 8 & .202 \\
3. 2-person oblique pull up bed & .594 & 8 & .569 \\
4. Single person pull up bed & 1.362 & 19 & .189 \\
\hline
\end{tabular}

\subsubsection{Individual load per transfer}

Shapiro-Wilks test showed normal distribution $(n=21, p>.05)$. A repeated measures ANOVA showed the mean average individual force differed significantly between the conditions $(\mathrm{F}(2.21,44.21)=27.26, \mathrm{p}<.05)$. Post hoc tests revealed significant differences between condition 3 and the other conditions $(1: \mathrm{p}=.000,2: \mathrm{p}=.000$, $4: \mathrm{p}=.000)$ and condition 2 and $4(\mathrm{p}=.047)$. The two person oblique was significantly lower in force exerted, with the same being said for condition 4 and 2. An Independent-Samples T-test compared the individual forces between novice and expert participants. For condition 1, though Levene's test was violated ( $\mathrm{F}=5.49$, $\mathrm{p}=.03$ ), there proved to be a significant difference in force for novice and expert participants $(\mathrm{p}=.001)$. Although all of these calculations suggest novice participants exert more force during each condition than their expert counterparts, only conditions 1 and 2 alter significantly.

Table 7. Mean Average Individual Load

\begin{tabular}{lcccccc}
\hline \multicolumn{1}{c}{ Condition } & \multicolumn{2}{c}{ Novice } & \multicolumn{2}{c}{ Expert } & \multicolumn{2}{c}{ Combined } \\
& Mean & SD & Mean & SD & Mean & SD \\
\hline 1. Parallel stepping & 92.3 & 12.3 & 61.8 & 21.7 & 76.3 & 23.4 \\
2. Rotation & 109.5 & 35.9 & 80.5 & 27.5 & 94.3 & 34.3 \\
3. 2-person oblique pull up bed & 42.3 & 10.8 & 38.3 & 6.1 & 40.2 & 8.7 \\
4. Single person pull up bed & 78.6 & 21.9 & 68.0 & 13.0 & 73.0 & 18.2 \\
\hline
\end{tabular}

Table 8. Results From Independent Samples T-test For Novice Vs. Experts For Individual Force Per Transfer

\begin{tabular}{|lccc|}
\hline \multicolumn{1}{|c}{ Condition } & $\mathrm{t}$ & $\mathrm{df}$ & $\begin{array}{c}\text { Sig. } \\
\text { (2-tailed) }\end{array}$ \\
\hline 1. Parallel stepping & 4.011 & 16.135 & .001 \\
2. Rotation & 2.091 & 19 & .050 \\
3. 2-person oblique pull up bed & 1.054 & 19 & .305 \\
4. Single person pull up bed & 1.362 & 19 & .189 \\
\hline
\end{tabular}




\subsubsection{Individual hand load}

For the individual hand load data, a Wilcoxon Signed-Rank test was used to compare the hand force data. The results indicated that for conditions $1(\mathrm{Z}=-2.03, \mathrm{p}=.042)$ and $2(\mathrm{Z}=-2.2, \mathrm{p}=.028)$ the left hand scores were, statistically higher than the right hand scores. However for condition $3(\mathrm{Z}=-2.0, \mathrm{p}=.046)$, right hand scores were, statistically higher than the left hand scores.

To compare novice and expert participants a Mann-Whitney U test showed that for the left hand in condition 1 the force exerted by the novice participants was significantly greater than that of the expert participants $(U=8, p=.001)$. However for all of the other sets of data, there was no statistically significant difference between novice and expert participants ( $>>$.05). This suggests the level of experience does not have an effect on reducing the force exerted when considering each hand individually.

The same process was completed to compare the hand up vs. down the bed for conditions 1 and 2. The ANOVA determined that the force exerted significantly differed statistically between conditions $(F(1,20)=6.97, \mathrm{p}<.05)$. However there was no statistically significant difference between the force exerted and hand positions $(\mathrm{F}(1,20)=.128, \mathrm{p}=.724)$, as well as no significant interaction between the condition and hand position $(\mathrm{F}(1,20)=.186, \mathrm{p}=.671)$.

A Paired Samples T-test was conducted to compare hand positions the force exerted for up vs. down the bed. This analysis suggested that the location of the hand in relation to the bed does not have an impact on the amount of force exerted during the transfer, even though in these conditions the force exerted by the bottom hand was slightly greater than that exerted by the hand up the bed.

\section{Discussion}

The rotation movement was clearly perceived to be the transfer that required the greatest amount of force to be exerted. It was also understood to be the least comfortable and safe, which was due to the fact that it caused the participant to twist their body. These findings are backed up by various regulations and guidelines which state the dangers of twisting the body when handling a load/ patient. There was a very strong correlation between comfort and safety. Meaning the more comfortable the participant felt completing the transfer, the safer they felt the transfer was. With patients feeling safer and more comfortable if the transfer used a safe technique according to a work technique score. The expert participants recorded a positive correlation between individual and organisational acceptance, however further research would have to be conducted to explore the cause of this correlation.

There was a large variation in the recorded data, which was due to individual differences between participants. Other similar studies quantifying the force of patient handling tasks have similarly reported variations and inconsistencies due to the natural form of humans. Even with these differences there was differences between each 
condition and the novice and expert participants. Physically there were interesting findings between the conditions: when comparing the total load per transfer the transfers with the participants at the head of the bed showed lower forces; similarly for individual load per transfer it was found that condition 3 was lower than the other conditions. This suggests that less force is needed in transfers where the patient is pulled towards the carer. This statement is backed up by the findings of McGill and Kavcic (2005); unsurprisingly, the use of two carers reduced the force needed to complete the transfer per individual.

The results from individual hands were less convincing. When looking at individual hand loads and comparing the force exerted by the left and right hands, there were some differences between the different positions. The data suggested that when participants are at the side of the bed they exerted more force using the left hand/ arm when compared to the right hand/ arm. However, when at the top of the bed the right hand/ arm, was more dominant. This could suggest that for 'pulling' transfers the dominant hand contributes more, however more research would have to be conducted to confirm this.

\subsection{Concluding Remarks}

It was found that novice participants exerted more force during the transfer than their expert counterparts, however only some of these factors proved to be significant. This suggests that the level of experience and training could be related to the amount of muscle activity used in the transfer (Keir and McDonell, 2004). Nevertheless, as only some were significant it suggests training does not influence force exertion resulting in musculoskeletal problems (Johnsson et al., 2002).From the results it was found that, although none of the conditions posed an immediate threat to the carers wellbeing, there was a statistically significant reduction in the amount of force exerted for the two conditions at the head of the bed when compared to the two at the side. In particular the rotation task was significantly harder and perceived as such by the participants and should be avoided in transfers tasks. When taking these results into the healthcare environment, it would suggest that, where possible, carers partake in transfer from the head of the bed, using their own weight as an aid to pull the patient up the bed. Doing so would help reduce the risk of developing musculoskeletal injuries.

\section{References}

Alamgir, H., Cvitkovich, Y., Yu, S., Yassi, A., (2007). Work-related injury among direct care occupations in British Columbia, Canada. Occup. Environ. Med. 64 (11), 769-775.

American Nurses Association (ANA.) (2013). Safe patient handling and mobility. 1st ed. Silver Spring, Md.: American Nurses Association. [online] Available at: http://www.nursesbooks.org/ebooks/download/SPHM-Standards.pdf Black T, Shah S, Busch A et al (2011). Effect of transfer, lifting and repositioning (TLR) injury prevention program on musculoskeletal injury among direct care workers. Journal of Occupational Environmental Hygiene, 8(4): 226-235.

Brooks, A. \& Orchard, S. (2011). Core person handling skills. In J. Smith, (Ed.). The Guide to the Handling of People: A systems approach (6th ed.) (See moving up the bed, pp. 139-142). Middlesex, UK: BackCare. 
Cohen. M.H., Nelson. G.G., Green. D.A., et al. (2010) Patient Handling and Movement Assessments: A White Paper. Dallas, Texas: The Facility Guidelines Institute.

Fray, M.J. and Hignett, S., 2015. An evaluation of the biomechanical risks for a range of methods to raise a patient from supine lying to sit- ting in a hospital bed. 19th Triennial Congress of the IEA, Australia, 9th-14th August 2015.

Garg, A., Kapellusch, J.M., 2012. Long-term efficacy of an ergonomics program that includes patient-handling devices on reducing musculoskeletal injuries to nursing personnel. Hum. Factors 54 (4), 608-625.

Garg, A., Owen, B., Beller, D., et al. (1991). A biomechanical and ergonomic evaluation of patient transferring tasks: bed to wheelchair and wheelchair to bed. Ergonomics; 34: 289- 312. ISO 11228-2. (2007). Ergonomics-Manual handling-Part 2: Pushing and pulling . Geneva: International Organization for Standardization.

ISO. 2012. Ergonomics- Manual handling of people in the healthcare sector: an edited summary of ISO Technical Report 12296.

Jäger, M., Jordan, C., Theilmeirer, A., Wortmann, N., Kuhn, S., Nienhaus, A. and Luttmann, A. (2012). Lumbar-Load Analysis of Manual Patient-Handling Activities for Biomechanical Overload Prevention Among Healthcare Workers. The Annals of Occupational Hygiene, 57(5), pp.528-544.

Johnsson, C., Carlsson, R. and Lagerström, M. (2002). Evaluation of training in patient handling and moving skills among hospital and home care personnel. Ergonomics, 45(12), pp.850865.

Jordan, C., Luttmann, A., Theilmeier, A., Kuhn, S., Wortmann, N. and Jäger, M. (2011). Characteristic values of the lumbar load of manual patient handling for the application in workers' compensation procedures. Journal of Occupational Medicine and Toxicology, [online] 6(1), p.17. Available at: https://occup-med.biomedcentral.com/articles/10.1186/1745-6673-6-17 Keir, P. and MacDonell, C. (2004). Muscle activity during patient transfers: a preliminary study on the influence of lift assists and experience. Ergonomics, 47(3), pp.296-306.

Lim H, Black T, Shah S et al (2011). Evaluating repeated patient handling injuries following the implementation of a multi- factor ergonomic intervention program among health care workers. Journal of Safety Research, 42: 185-191.

McGill, S. and Kavcic, N. (2005). Transfer of the horizontal patient: The effect of a friction reducing assistive device on low back mechanics. Ergonomics, 48(8), pp.915-929.

Nelson, A., Lloyd, J.D., Menzel, N., \& Gross, C. (2003). Preventing nursing back injuries: redesigning patient handling task. AACHN Journal. 51(3). 126-134.

NHS. (2010). Guidance for the Moving and Handling of patients and inanimate loads (version 3). [online]. Available at:

http://www.leicestercity.nhs.uk/library/hs010guidanceformovingandhandlingv3d2final.pdf Owen, B.D., \& Staehler, K.S. (2003). Decreasing back stress in home care. Home healthcare nurse. 21(3). 180-186.

Pellino, T.A., Owen, B., Knapp, L., \& Noack, J. (2006). The evaluation of mechanical devices for lateral transfer on perceived exertion and patient comfort. Orthopedic Nursing. 25(1). 4-10. Schibye, B., Hansen, A.F., Hye-Knudsen, C.T., Essendrop, M., Bocher, M., Skotte, J., 2003. Biomechanical analysis of the effect of changing patient-handling technique. Appl. Ergon. 34 (2), 115-123.

Smith, J. (2005). The guide to the handling of people. $5^{\text {th }}$ ed. Teddington, Middlesex: BackCare.

Smith, J. (2011). (Ed.) The Guide to the Handling of People: A systems approach (6th ed.) Middlesex, UK: BackCare.

Warming S., Precht D., Suadicani P., Ebbehoj N. (2009). Musculoskeletal complaints among nurses related to patient handling tasks and psychosocial factors - Based on logbook registrations. Applied Ergonomics 40: 569-576

Waters, T.R,. (2007) When is it safe to manually lift a patient? Am J Nurs ; 107: 53-8; quiz 59. 